\title{
SEXUAL DIMORPHISM OF HUMAN HYOID BONE
}

\section{Poonam Vohra ${ }^{1}$, Pratima Kulkarni ${ }^{* 2}$.}

${ }^{1}$ Professor \& HOD, Department of Anatomy, Sakshi Medical College, Guna, Madhya Pradesh, India.

${ }^{2}$ Associate Professor, Department of Anatomy, Govt. Medical College, Aurangabad, Maharashtra, India.

\section{ABSTRACT}

Introduction: In the medicolegal cases as well as archeological studies bone examination performs very useful roll. It is also useful in determination of personal identity. Next to the enamel of teeth, bones of the body are the last to perish after death. Hence in establishing the personal identity with respect to sex, age and stature, Anatomist and anthropologist use the skeletal material for giving their opinion [1]. Anthropometric studies of different bones and parts of body shows definite sexual dimorphism in male and female; which has been already explained by various authors ${ }^{7}$. However in the present work is an attempt to establish importance of hyoid bone in sex identification, both in medicolegal and anthropometric study.

Materials and Methods: Present study done with 300 hyoid bones collected from medicolegal post mortem cases conducted by experts of Forensic Medicine \& Toxicology Department, Government Medical College, Aurangabad, Maharashtra, India.The various parameters of hyoid bone were noted with the help of Digital Vernier Calliper.

Results and Conlucsion: By multivariate discriminant linear functional analysis of present study shown that $94 \%$ male and $85 \%$ female hyoids could be identified correctly, this degree of accuracy explaining that role of hyoid bone in determination of sex. The total percentage of male and female hyoids identified by multivariate discriminant analysis is found to be $92 \%$.

KEY WORDS: Sexual Dimorphism, Hyoid, Anthropometry.

Address for Correspondence: Dr. Pratima Kulkarni, Associate Professor, Department of Anatomy, Govt. Medical College, Aurangabad, Maharashtra, India.

E-Mail: poonambhatraj@gmail.com

\section{Access this Article online}

\section{Quick Response code $\quad$ Web site: International Journal of Anatomy and Research \\ ISSN 2321-4287 \\ www.ijmhr.org/ijar.htm}

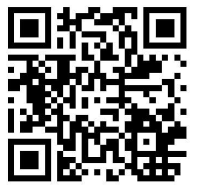

DOI: $10.16965 /$ ijar.2017.118
Received: 21 Jan 2017

Peer Review: 22 Jan 2017

Revised: None
Accepted: 24 Feb 2017

Published (O): 31 Mar 2017

Published (P): 31 Mar 2017

\section{INTRODUCTION}

The examination of bones also helps in the study of archeological specimen obtained after excavation, as well as in medicolegal cases for establishing the personal identity. Next to the enamel of teeth, bones of the body are the last to perish after death. Hence in establishing the personal identity with respect to sex, age and stature, Anatomist and anthropologist use the skeletal material for giving their opinion.The exact establishment of identity of sex in archeo- logical and medicolegal samples of bones, depends on the number of bones sent for examination. It was observed by Taylor in his book of 'Medical Jurisprudence', that the number of bones was a) Skull + Femur $=97.35 \%$ b) Coccyx and sacrum $=97.18 \%$ c) Pelvis $=95.00$ $\%$ (d) Skull bone alone $=91.38 \%$ e) Femur $=39.84$ $\%$ f) Atlas Vertebrae $=31.18 \%$ [5-18]. However, Anthropometric studies of different bones and parts of body shows definite sexual dimorphism in male and female; which has been explained 
by Stanfield's postulation of evolutionary biology (1977) which says that the genotype (phenotypic) variance is inversely proportional to the intensity of establishing selection. This will explain the difference in the morphology of adult human male and female. Morphological features of the bones also depends on the nutritional, geographical and occupational factors [1-5]. Till now, the various workers have quoted that skull and pelvis are of much help in identification of the sex of the skeletal material. However it was observed that minimal work has been done on the bone hyoid. Hence the present work is an attempt to establish some of the parameters which will be useful in sex identification, both in medicolegal and anthropometric study.

\section{AIMS AND OBJECTIVES}

The present study is aimed to study

a) The sexual dimorphism in adult human hyoid.

b) The utility and limitations of various hyoid parameters and indices in the sex differentiation.

c) To compare the results with previous studies.

\section{MATERIALS AND METHODS}

Fig. 1 \& 2: Anterosuperior View of hyoid bone indicating various measurement points.

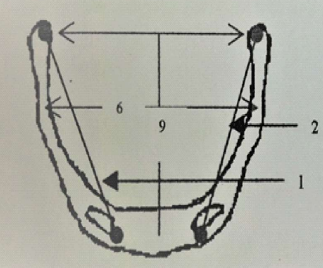

Fig. 1.

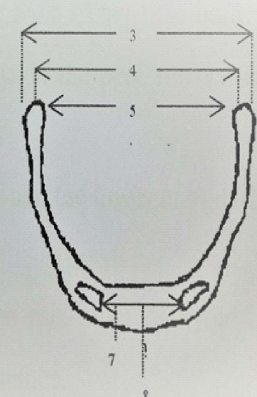

Fig. 2.
Hyoid bones (300) of known age and sex were collected from medicolegal post mortem cases conducted by experts of Forensic Medicine \& Toxicology Department, Government Medical College, Aurangabad, Maharashtra, India. Out of 300 hyoid bones 250 were of adults (130 males and 120 females) and 50 were of children (25 males and 25 females).Age, Weight, Sex, Supine length of cadavers was recorded at the time of autopsy. Fractured hyoids were deleted from the cases. i) The various parameters of hyoid bone were noted with the help of Digital Vernier Calliper. The method of measurement of various parameters of hyoid bone which considered in this study are shown in Fig $1 \& 2$. In Fig 1: A: length of greater cornu; B: Distance between the internal surfaces of the greater cornu at their middle; C: Vertical distance between middle of anterior surface of body and transverse line drawn between tubercles of greater cornu in the midline.D: Height of body of hyoid in its middle.

In Fig 2: E,F,G: Transverse distance between the tubercles of greater cornu (external, middle \& internal); $\mathbf{H}$ : Minimum transverse distance between bases of lessor cornu ; I:Distance between the upper and lower margins of body in the middle.

At the first instance all these measurements were tabulated and statistically analysed with the help of SPSS software. The values of the mean and standard deviation were obtained. A multivariate discriminatory linear function analysis also has been applied to the same data and the linear functions have been obtained as the second part of the present study. Comparison between the results obtained by the multivariate analytical method and the routine statistical method for discriminating the sex of the Hyoid has been done.

\section{OBSERVATIONS \& RESULTS}

In the present study we observed and prepared tabulated results considering all parameters of hyoid bone.

Table 1: Various measurements of Hyoid bone in adult males and females (13-80 years).

\begin{tabular}{|c|c|c|c|c|c|c|}
\hline \multirow{2}{*}{\multicolumn{2}{|c|}{ MEASUREMENTS }} & \multicolumn{2}{|c|}{ MALES } & \multicolumn{2}{|c|}{ FEMALES } & \multirow{3}{*}{$\frac{\text { P Value }}{<0.001}$} \\
\hline & & \multirow{2}{*}{$\frac{\text { MEAN } \pm \text { SD }}{31.84 \pm 3.62}$} & \multirow{2}{*}{$\frac{\text { RANGE }}{22-41}$} & \multirow{2}{*}{$\begin{array}{c}\text { MEAN } \pm \text { SD } \\
28.62 \pm 3.22\end{array}$} & \multirow{2}{*}{$\frac{\text { RANGE }}{22-37}$} & \\
\hline Length of & Right & & & & & \\
\hline Cornue & Left & $31.87 \pm 3.84$ & $23-41$ & $28.4 \pm 3.44$ & $22-39$ & $<0.001$ \\
\hline \multirow{3}{*}{$\begin{array}{c}\text { Transverse } \\
\text { Distance } \\
\text { between } \\
\text { tubercles } \\
\text { of greater } \\
\text { cornu } \\
\end{array}$} & External & $40.21 \pm 5.71$ & $26-52$ & $36.16 \pm 4.9$ & $25-52$ & $<0.001$ \\
\hline & Middle & $37 \pm 5.7$ & $22-48$ & $33.26 \pm 5$ & $21-48$ & $<0.001$ \\
\hline & Internal & $33.89 \pm 5.53$ & $18-45$ & $30.59 \pm 5.08$ & $18-45$ & $<0.001$ \\
\hline \multicolumn{2}{|c|}{$\begin{array}{l}\text { Distance between } \\
\text { internal surfaces of } \\
\text { greater cornu at their } \\
\text { center. }\end{array}$} & $35.52 \pm 3.82$ & $22-44$ & $32.28 \pm 4.34$ & $20-44$ & $<0.001$ \\
\hline \multicolumn{2}{|c|}{ Width of hyoid } & $25.94 \pm 3.47$ & $18-38$ & $25.05 \pm 30.95$ & $20-37$ & $<0.05$ \\
\hline \multicolumn{2}{|c|}{ A-P Diameter of body } & $3.67 \pm 0.9$ & 2-Jun & $3.4 \pm 0.76$ & 2-May & $<0.001$ \\
\hline \multicolumn{2}{|c|}{ Height } & $11.01 \pm 1.65$ & $9.0-15$ & $10.54 \pm 1.62$ & $8.0-15.0$ & $<0.001$ \\
\hline
\end{tabular}


Table 2: Various measurements of Hyoid bone in children males and females (0-12 years).

\begin{tabular}{|c|c|c|c|c|c|c|}
\hline \multirow{2}{*}{ MEASUREMENTS } & \multicolumn{2}{|c|}{ MALES } & \multicolumn{2}{c|}{ FEMALES } & \multirow{2}{*}{ P Value } \\
\cline { 2 - 6 } & MEAN \pm SD & RANGE & MEAN \pm SD & RANGE & \\
\hline $\begin{array}{c}\text { Length of } \\
\text { Greator Cornue }\end{array}$ & Right & $22.3 \pm 3.26$ & $13-28$ & $21.96 \pm 2.22$ & $18-27$ & $<0.001$ \\
\cline { 2 - 7 } & Left & $22.8 \pm 3.1$ & $14-26$ & $22.76 \pm 1.83$ & $17-26$ & $<0.001$ \\
\hline \multirow{4}{*}{$\begin{array}{c}\text { Transverse } \\
\text { Distance } \\
\text { between } \\
\text { tubercles of } \\
\text { greater cornu }\end{array}$} & External & $30.4 \pm 4.57$ & $24-36$ & $29.88 \pm 4.09$ & $24-36$ & $<0.001$ \\
\cline { 2 - 7 } & Middle & $28 \pm 4.49$ & $22-36$ & $27.2 \pm 4.59$ & $21-34$ & $<0.001$ \\
\cline { 2 - 6 } & Internal & $25.92 \pm 4.49$ & $20-34$ & $24.84 \pm 4.33$ & $20-31$ & $<0.001$ \\
\hline $\begin{array}{c}\text { Distance between internal } \\
\text { surfaces of greater cornu at } \\
\text { their center. }\end{array}$ & $24.28 \pm 3.82$ & $15-34$ & $23.12 \pm 5.91$ & $14-31$ & $<0.001$ \\
\hline \multicolumn{2}{|c|}{ Width of hyoid } & $18.5 \pm 3.38$ & $13-27$ & $18.2 \pm 4.12$ & Dec-27 & $<0.05$ \\
\hline A-P Diameter of body & $3.4 \pm 1.2$ & $2-$ May & $3.6 \pm 1.25$ & $1-$ May & $<0.001$ \\
\hline \multicolumn{2}{|c|}{ Height } & $12.2 \pm 2.57$ & Sep-19 & $10.48 \pm 2.58$ & May-15 & $<0.001$ \\
\hline
\end{tabular}

From Table 1\& 2 Mean and Standard Deviation of the measurements of the Hyoid bone in the adult (males and females) \& child (males and females) can be seen. In adults all the measurements were found to be greater in the males than the females. Sexual difference between the mean of every measurement was either highly significant $(P<0.001)$.In children considerable increase in measurements was noticed till the age of 12 years. Sexual differences were insignificant upto the age of 12 years, but thereafter in the males the measurements increase still further till the age of 25 years. In the females above 12 years slight increase was noticed till the age of 20 years but no increase occurred thereafter. A multivariate linear discriminant analysis technique of Armitage (197l) was applied to measurements of all parameters with the help of SPSS software. The formula for derivation of linear function is given as : $Z=b_{0}$ $+b_{1} x_{1}+b_{2} x_{2}+b_{3} x_{3}+b_{4} x_{4}---b_{10} x_{10}+b_{11} x_{11}$.

Where $b_{0}$ is the constant, $b_{1}$ to $b_{11}$ are the coefficients and $X_{1}$ to $X_{11}$ are the variables. The values of $b_{1}$ to $b_{11}$ were obtain by using SPSS program.

$Z=(-14.136)+(5.069) X_{1}+(-0.052) X_{2}+(0.077)$ $\mathrm{X}_{3}+(0.032) \mathrm{X}_{4}+(0.027) \mathrm{X}_{5}+(-0.02) \mathrm{X}_{6}+(0.042)$ $x_{7}+(0.032) x_{8}+(0.144) x_{9}+(0.083) x_{10}+(0.062)$ $\mathrm{X}_{11}$

The mean values of $Z_{m \text { (Male) }}$ and $Z_{f(\text { Female) }}$ were 1.33108 and -1.35359 respectively. With the use of Armitage method calculated $Z_{0}$ value is 0.11024 . When values for given specimen are analysed as above taking $Z_{0}$ as sectioning point, if $Z>Z_{0}$ the bone belongs to male and $Z<Z_{0}$ it belongs to the female.

For all the mentioned samples of male, value of $Z_{m}$ is greater than value of $Z_{o}$ except in the case of $\mathrm{Zm}_{18}$ which is less than $\mathrm{Z}_{0}$. So the percentage of hyoids sexed correctly by using this method is $94 \%$. Similarly, all values of $z_{f}$ are less than value of $Z_{o}$, except $Z_{f 16}$ which is greater than $Z_{0}$ . So the percentage of hyoids correctly sexed by using this method is $89 \%$. On the basis of this analysis $94 \%$ male and $89 \%$ female adult hyoid bones could be classified accurately by taking into consideration the complete set of all the measurements mentioned earlier.

\section{DISCUSSION}

The value of determining the sex of the hyoid is mostly medico-legal were $100 \%$ accuracy is required. Jit and Singh [9], found that the maximum and minimum limits of parameter values which could be determined on the basis of Mean \pm 3 SD. were called Demarking Points (DP). These D.P. were of great value in determiningthe sex of hyoid which gave almost $100 \%$. They found that results for all parameters were highly significant $(p<0.001)$.Similarly in present study we also found that $p$ value for all parameters was highly significant $(p<0.001)$ except one parameter i.e. width of body of hyoid was comparatively less significant $(p<0.05)$.We also found that the hyoid bones exhibit racial difference in all parameters having smaller size in all variables as compared to that bones taken in study done by Harjeet and Jit. Thus this factor is of great importance while considering sexual dimorphism of a given particular bone, as it may create an error in identification of sex of the hyoids obtained from other region or race.

In study done by Kothapalli D \& Kumari P they observed that greater cornu length of both right and left sides, transverse distance between tubercles of greater cornu, length of lesser cornu on both right and left sides, transverse distance between of lesser cornu, height of body of hyoid bone, were somewhat more in males than females which are either highly significant ( $p$ $<0.001$ ) which is very similar to the results of present study [1]. 
Reesink $\mathrm{E}$ and Immerseel V done study on hyoid bone for sexual diamorphism and observed that there was borderline insignificance in parameters of hyoid taken under study.This may be due to the small test sample. They concluded that the morphometric analysis of the hyoid bone is a helpful technique in the sex determination of human skeleton [4].

In a study done by Mukhopadhyay P they observed that the size and shape of hyoid bone was larger in males regarding width, anteroposterior length and slope of cornu. Using unpaired t-Test with alpha level of 0.05 the only length of greater cornu was found to be not significantly different in the male and female $(p=0.116)$.This result is also quite similar with our results [2].

\section{CONCLUSION}

On subjecting all the parameters to multivariate discriminant linear functional analysis $94 \%$ male and $85 \%$ female hyoids could be identified correctly. When the parameter which was statistically less significant was deleted from the analysis, the results obtained were more accurate than, when it was included. Thus the total percentage of male and female hyoids identified by multivariate discriminant analysis is found to be $92 \%$. Identification of male bone in this study was $94 \%$ which shows higher degree of accuracy explaining that role of hyoid bone in determination of sex.

\section{Conflicts of Interests: None}

\section{REFERENCES}

[1]. Kothapalli P, Kumari P. Sexual Dimorphism Of Hyoid Bone. Journal of Bioscience And Technology. 2015; Vol 6(2):653-657.

[2]. Mukhopadhyay P. Morphometric features and sexual dimorphism of adult hyoid bone: A population specific study with forensic implications. Journal of Forensic and Legal Medicine. 2010;17(6):321-324.

[3]. Durga k.Sexual dimorphism of hyoid bone. Journal of Bioscience And Technology.Biosci Tech. 2015;6(2):653-657.

[4]. Reesink E, Van Immerseel A, Brand R, Bruintjes T. Sexual dimorphism of the hyoid bone?. International Journal of Osteoarchaeology. 1999;9(5):357-360.

[5]. Taylor A.The Principles and Practice of Medical Jurisprudence.J\&A Churchill London.Oxford Pub.1983; Vol 1.
[6]. Funnanik F.Relation Of Some Dimensions Of The Middle Part Of The Laryngeal Cavity To Span Of The Greater Horns Of The Hyoid Bone. Folia Morphologica.1976;35:123-131.

[7]. Hrd1icka, A.Practical Anthropometry, Winster Institude Philadephia, quoted by Krogman (1962).

[8]. Jamison.A Univariate \& Multivariate Examination Of Measurement Error In Anthropometry. Am. J. Phys. Anthrop.1974;40:197-204.

[9]. Jit I, Singh.The Sexing of Adult Clavicles,Ind.I. Med. Research.1966;54: 551-571.

[10]. Komenda S. Sex Determination From The Hyoid Bone By Means Of Discriminant Analysis. Aota Universitatis Palackianae Olumubensis Facultatis Medical.1990;37-50.

[11]. Lykakj G.The Ossified Hyoid Apparatus, Morphology Interpretation, Clinical And Functional Significance. Anatomischer Anzeiger.1988;166:187-193.

[12]. Papadopoulas N. The Shape And Size Of Human Hyoid Bone And A Proposal For An Alternative Classification: Sex Differences In Pubic Bone of Bantu Bushman.Journal Of Anatomy.1989;166(2):249-260.

[13]. Pearsons. On Problem Of Sexing Osteometric Material. Biometrica. steel, F.L.D. 1915;10(2):479-481, cited by.(I 962).

[14]. Ranjith C.A Postmortem Study Of One Hundred Hyoid Bones Using Weight As A Parameter.Journal Of Indian Academy of Forensic Medicine.1988;10(2):31-33.

[15]. Ronald L. Age and Ossification of hyoid bone : forensic implications. Journal of forensic sciences.1987;32(2):1655-1659.

[16]. Sahana', SN.Human Anatomy Descriptive And Applied, Central Book Agency-Calcutta.1980.

[17]. Singh S, Rain P. Identification Of Sex From The Hipbone, Demarking Points. J. Anat. Soc. Ind.1977;26:111-117.

[18]. Gray's Anatomy. 37th ed. Churchill Livingstone. Williams and Warwick Editors.1987.

How to cite this article:

Poonam Vohra, Pratima Kulkarni. SEXUAL DIMORPHISM OF HUMAN HYOID BONE. Int J Anat Res 2017;5(1):3607-3610. DOI: 10.16965/ijar.2017.118 